\title{
EDUCACIÓN DE LAS EMOCIONES ¿UN REIO?
}

Diego Collado Femández $z^{1}$ y Cristina Cadenas Sánchez ${ }^{2}$

1Profesoren la Facultad de Ciencias de la Educación y del Centro de Magisterio "La Inmaculada". Universidad de Granada. Email: dcollado@ugr.es

2Diplomada en Magisterio de Educación Física. Universidad de Granada. Email: cristina.cadenas.sanchez@gmail.com

RESUMEN: El artículo pretende contextualizar la situación actual de la sociedad desde una perspectiva emocional, estableciendo la importancia del desarrollo de la inteligencia emocional en todas las etapas de la vida y centrándose en el ámbito educativo da do el papel que ejerce a la hora de transmitir hábitos, emociones y actitudes. Actualmente, tanto en el sistema educativo como en la sociedad, se le da una mayor importancia a los aspectos cognitivos, a los conocimientos, al saber, que a los sentimientos, al ser. Es por ello por lo que tratamos de dar un vuelco a esta mentalidad o balanza, proponiendo un trabajo en el aula de búsqueda interior a través del yoga y otros elementos que propician el desarrollo persal, partiendo de las emociones producidas por el niño como medio para identificarse y conocerse. De esta forma y desarrollando esta dimensión de la personalidad moral, se produce un bienestar personal, social, psicológico y físico. Y al hablar de bienestar no podemos obviar el témino felicidad, que será trabajado desde una visión emocional observando los beneficios que nos reportan actividades como la risoterapia.

PALABRAS CLAVE: Emoción, Felic idad y Educa ción. 


\section{1.- INTRODUCCIÓN}

A lo largo de la evolución humana, el hombre ha venido persiguiendo la necesidad de sentirse bien con él mismo y con su entorno. A pesar de que se conoce que en algunas etapas de su historia se ha alcanzado dicho fin, éste encuentro ha sido deficitario o insuficiente para poder lograr un conocimiento y consecuentemente enriquecimiento de sus virtudes.

El poder conseguir este objetivo, consideramos que es el tesoro anhelado por todos pero encontrados por pocos. Así, lo consideramos como uno de los grandes retos de nuestra humanidad, por el que cada ser humano debe luchar y crear su futuro en base a la búsqueda de sus emociones. Para ello, como veremos en el desarrollo de este artículo, se ha de centrar en dar sentido a la vida, en buscar qué es lo que le motiva a dar cada día un paso más en su existencia, en querer SER, etc.

En la sociedad en la que vivimos, este camino que estamos describiendo, parece que proviene de otra etapa de la vida para la que no estamos formados o concienciados. El hecho de que prevalezcan las emociones, los sentimientos, el aspecto interior frente a los conocimientos, procedimientos, procesos cognitivos, no son de las corrientes actuales que se divulgan en la sociedad del siglo XXI.

Cuando el hombre imagina y se deja llevar por sus sueños, alcanza el mayor estado de motivación que ningún otro ser vivo puede igualar, esto hace que en su interior se cree un pequeño motor que impulsa su existencia para alcanzar un estado del alma más agradable y ameno consigo mismo y con los demás. Es en este momento cuando el hombre inicia su búsqueda por la felicidad.

Partiendo de esta meta, de la búsqueda de las emociones con la finalidad de trabajar nuestra inteligencia emocional y con ella, desarrollar actitudes positivas y bienestar, os invitamos a reflexionar sobre la importancia del trabajo interior tanto en el ámbito educativo como en cualquier instancia de la vida social.

\section{2- HACIA UNA CONSTRUCCIÓN DE LA INTELIGENCIA EMOCIONAL}

Como es de suponer, existen numerosas definiciones sobre éste término en función de los autores e ideologías de los mismos. Etimológicamente emoción proviene de moveré que significa moverse, lo que supone una percepción de atracción y repulsión consciente y una conducta de acercamiento o aversión.

Autores como Daniel Goleman, en 1995, la definen como la capacidad para reconocer sentimientos en sí mismo y en otros, siendo hábil para manejarlos al trabajar con otros.

Mayer, Salovey y Caruso (2000), afirman que es la capacidad de percibir y expresar emociones, de asimilar las emociones en el pensamiento, de comprender y razonar con las emociones y de regular las emociones en uno mismo y en los demás.

Emily Sterrett (2002) hace referencia al conjunto de destrezas de gestión de personal y destrezas sociales que nos permiten triunfar en el puesto de trabajo y en la vida en general. 
Pablo Fernández-Berrocal (2004) la define como la capacidad de percibir, comprender y regular las emociones propias y las de los demás.

En general, la inteligencia emocional podríamos definirla como un compendio de emociones y sentimientos que por medio de una serie de habilidades nos permiten reconocer tanto nuestras sensaciones como las de los demás. Por ende, es fundamental para hacer un uso efectivo de las emociones, el saber identificarlas y reconocerlas.

El concepto de inteligencia emocional se comenzó a conocer popularmente de forma reciente, sin embargo, ya en el año 1920 se pueden encontrar los primeros indicios que hacían referencia a este concepto, con el psicólogo Edward Thorndike y su término inteligencia social, que definió como la habilidad para comprender y dirigir a los hombres y mujeres y actuar sabiamente en las relaciones humanas. Además, afirmaba que existía dos tipos de inteligencias: la abstracta que consistía en la habilidad para manejar ideas y la mecánica que se centraba, en cambio, en entender y manejar objetos.

En los últimos cincuenta años, se han llevado a cabo miles de estudios relacionados con el desarrollo de las capacidades del cociente emocional en los niños. Dichas investigaciones analizan los componentes que forman el consciente emocional de una persona y, en alguna de ellas, llegan a concluir que puede medirse mediante test de inteligencia estandarizados, como ocurre con las escalas de inteligencia de Wechsler.

Desde nuestra perspectiva, consideramos que para determinar el coeficiente emocional no ha de basarse tan solo en aspectos cuantitativos y estandarizados como pueden ser escalas o instrumentos creados para tal fin, sino que para establecer el grado de la misma, hay que conocer a la persona, profundizar en técnicas de conocimiento a sí mismo y no enfatizar y resaltar aspectos fijándose tan solo en los resultados proporcionados por diversos métodos.

Mayer, Caruso y Salovey (2000), consideran que la inteligencia emocional es aprendida y se desarrolla con la edad y la experiencia. Como mínimo se puede concebir la inteligencia emocional de tres formas: como rasgo de personalidad, como habilidad mental y como movimiento cultural.

El desarrollo emocional de las personas pasa por una serie de etapas en la que éstos reconocen sus emociones y las de los otros, concretándose en el Modelo de Habilidades de Inteligencia Emocional que presenta a su vez cuatro niveles: percepción, uso, comprensión y manejo de las emociones.

Es cierto que no podemos medir con facilidad gran parte de los rasgos sociales y de la personalidad, tales como la amabilidad, la ira, la tristeza, la confianza en sí mismo, el autocontrol o el respeto a los demás; los que sí podemos hacer es reconocerlos en los niños y destacar su gran importancia. Es aquí donde se encuentra el primer paso para la construcción de la inteligencia emocional.

\section{1.- Tipos de inteligencia emocional.}

Un antecedente a la inteligencia emocional fue la teoría de las inteligencias múltiples de Dr. Howard Gardner, de la Universidad de Harvard. Éste plantea que las personas tenemos siete tipos de inteligencias (lingüística, lógica, musical, visualespacial y kinestésica, interpersonal e intra-personal) que nos relaciona con el mundo. 
Entre todas ellas encontramos dos tipos de inteligencias relacionadas con la competencia social y emocional como son la inteligencia interpersonal y la inteligencia intra-personal.

Según Gardner, la inteligencia interpersonal se construye a partir de una capacidad nuclear para sentir distinciones entre los demás: en particular, contrastes en sus estados de ánimo, temperamentos, motivaciones e intenciones. En formas más avanzadas, esta inteligencia permite a un adulto leer las intenciones y deseos de los demás aunque se hayan ocultado.

Cuando una persona llega a ese estado de control que hace que pueda identificar tanto sus emociones como las de otras personas que tiene a su alrededor, consideramos que ya ha llegado a la meta de la que hablábamos anteriormente, es decir, que estamos ante un sujeto con una gran capacidad emocional y trasfondo interior. Así, a pesar de la dificultad que esto supone, este ejemplo nos valdría para categorizarlo en un estado de bienestar completo y holístico al que, trabajando y educando en ello, todos podremos conseguir.

Por otro lado, la inteligencia intra-personal, es el conocimiento de los aspectos internos de una persona: el acceso a la propia vida emocional y a la propia gama de sentimientos, la capacidad de efectuar discriminaciones entre las emociones y, finalmente ponerles un nombre y recurrir a ellas como un medio de interpretar y orientar la propia conducta. Ante esto y a modo de reflexión, nos cuestionamos ¿Qué mejor que conocerse a uno mismo?

La valoración de las habilidades que constituyen la inteligencia emocional, define el cociente emocional (CE). Sólo reflexionando sobre la importancia que las emociones tienen en nuestra vida cotidiana, constatamos lo que la mayoría de las veces marcan nuestras decisiones, sin apenas ser conscientes de ello.

Por tanto, podemos ver personas con un mayor dominio de su vida emocional que otras, es decir, por ejemplo, en el ámbito de la educación, hay alumnos que pese haber tenido un rendimiento académico muy suficiente, gracias a sus habilidades emocionales han tenido una vida exitosa. Esto nos hace constatar que es necesario prestar mayor atención a este tipo de destrezas que pueden marcar nuestra vida tanto o más que el Cociente intelectual (Cl).

\section{3- LAS DIMENSIONES DE LA PERSONALIDAD MORAL}

En la escuela, partiendo de ella como pilar básico en la adquisición y formación de hábitos y actitudes, se han de desarrollar numerosas técnicas cuyo objetivo sea una mejora de alguna de las facetas de la personalidad moral, bien sea la conciencia moral, el juicio moral, la empatía y toma de perspectiva social, los sentimientos y las emociones morales, el autoconocimiento o la autoestima, la autorregulación o el autocontrol, el mundo del os valores, el universo de los hábitos y las virtudes, y la apertura al sentido a través de unos rasgos concretos que caracterizan cada una de estas dimensiones que en el mundo educativo se intentan mejorar con diferentes técnicas.

Martínez y Puig (1991), resumen las dimensiones de la personalidad moral, así como los rasgos principales que las caracterizan: 
1. Conciencia moral: Se caracteriza por una conciencia y responsabilidad de las propias acciones, esto es, autonomía moral. El sujeto es juez y dueño de su propia conducta.

2. Juicio moral: Es la capacidad de diferenciar los que está bien de lo que está mal, aportando argumentos. Debemos fomentar e impulsar en los alumnos la capacidad crítica ante cualquier situación que le pueda afectar para llevar a cabo unas u otras emociones. Por tanto, se trata de adquirir criterios de juicio moral.

3. Empatía y toma de perspectiva social: Hablar de empatía, es hablar de uno mismo. Considerada como la capacidad para ponerse en el lugar del otro. Esto nos va a permitir compartir emociones, tanto positivas como negativas, sentir con el otro. El profesor ha de tener desarrollada esta cualidad, ya que como docente, y sobre todo, como persona, tiene que detectar y trabajar su inteligencia interpersonal para llegar a comprender las emociones, sentimientos, razones y motivaciones de otros.

4. Autoconocimiento y autoestima: Ambos conceptos muy relacionados con el trabajo emocional. Es la conciencia de uno mismo, clarificación de los propios valores e integración de la experiencia personal. En definitiva, se trata de sentirse a gusto o a disgusto con el propio modo de ser, de obrar, de actuar. En referencia a la autoestima, consideramos que es un factor clave para un buen ajuste emocional y cognitivo. En los últimos años, la literatura psicológica ha recomendado abundantemente que hagamos una valoración positiva de nosotros mismos, que nos queramos a nosotros mismos, que tengamos una autoestima elevada. De alguna manera se piensa que una autoestima favorable, es la mejor manera de prevenir los desajustes emocionales.

5. Autorregulación o control de uno mismo: Considerada la capacidad para dirigir por uno mismo la propia conducta o autonomía. Interviene en tres direcciones: conducta coherente con el propio juicio moral, adquisición de hábitos morales deseados y construcción de la propia manera de ser. Como señalaremos más adelante, el que cada persona pueda ser el director de su orquesta, es decir, controlarse a sí misma, es un trabajo prevalentemente de las emociones y de su interior.

6. Sentimientos y emociones morales: Impregnan, posibilitan y condicionan otras capacidades. Se trata de sentirse afectado por problemas ajenos. Muy relacionado con la empatía y compasión, responsabilidad, compromiso, autoestima, etc.

7. El mundo de los valores: Confieren unidad al sentir, pensar y actuar del sujeto. Valen en la medida en que se encarnan y cristalizan en experiencias concretas. Las personas aprendemos con las acciones, con los hechos y no solo con los conocimientos. De aquí se deriva que el aprendizaje ha de ser significativo y para el disfrute.

8. Hábitos y virtudes: Disposiciones individuales, estables y uniformes a querer el bien y a actuar de forma correcta. Se someten a la reflexión y se plasman en un determinado contexto. Están asociadas a la fuerza de voluntad para llevarlos a cabo y superar los obstáculos.

9. Apertura al sentido: Esta dimensión va más allá. Es un estado mental que hace que nos preguntemos el porqué y el para qué de la vida, su sentido y 
significado. Por el ritmo incansable que se vive en la sociedad actual (estrés, agobio, presión, etc) esta categoría se ha visto desplazada o alejada con respecto a las demás. Es así como la persona no tiene tiempo libre para dedicarse a sí mismo. Quizás, muchas de ellas, no es que no puedan tenerlo, sino que no quieren por el miedo a encontrarse.

Junto al estado mental se encuentra el estado espiritual a través del cual se percibe una armónica fusión con el mundo. Es aquí donde se tiene la esperanza en la búsqueda del sentido de nuestra vida, de nuestro ser.

Aclarados estos presupuestos y contextualizados en nuestro objeto de estudio, consideramos que en la actualidad la elección de unas técnicas u otras depende esencialmente de las capacidades o de las dimensiones de la personalidad que se quieran desarrollar y para ello se utilizan aquellas que se consideran idóneas independientemente del origen de las mismas.

Al educador le corresponde el papel de reflexionar sobre lo que pretende y asimismo, decidir de forma coherente qué estrategias va a llevar a cabo para alcanzar los objetivos que se propone, y mediante qué técnicas.

\section{4- LA COGNICIÓN Y LA EMOCIÓN}

En la sociedad actual vivimos a un ritmo vertiginoso donde dicamos escaso tiempo a reflexionar sobre nuestro mundo emocional debido, en gran parte, a que siempre se ha pensado que las capacidades intelectuales que posee una persona son las que le harán triunfar en la vida. Pero, ¿Y el cociente emocional? ¿Es tan importante como el intelectual?

Siempre se ha pensado que un alto cociente intelectual era determinante y único para que la persona tuviera éxito en la vida. De hecho, en el ámbito educativo, todos hemos vivido y experimentado los test o pruebas teóricas con la finalidad de medir los conocimientos o capacidades cognitivas de la persona. En base a esos resultados, en algunos momentos decisivos, la persona estaría encaminada hacia un éxito personal y profesional o, por el contrario, a un fracaso de la misma.

Y es que, tanto los padres como profesores y niños se preocupan desde que son pequeños en estas capacidades. De hecho, cuando nos referimos a cualquier alumno o persona, siempre tendemos a calificarlos en base a su rendimiento académico y obviamos los aspectos interiores. Siguiendo a Sánchez (2009), siempre se califica a los niños como inteligentes y despiertos sin hacer referencias a su idoneidad en el control de las emociones. De esta forma, nos resultaría raro escuchar del docente que el niño tiene un buen control de sus emociones.

Afortunadamente esta concepción se ha venido modificando hace unos años, atribuyendo, desde la aportación principalmente de Goleman, un valor importante a la inteligencia emocional para el éxito personal.

El alumnado emocionalmente inteligente no sólo será más hábil para percibir, comprender y manejar sus propias emociones, sino también será más capaz de extrapolar sus habilidades de percepción, compresión y manejo a las emociones de los demás. Extremera y Fernández (2004) consideran que "esta teoría proporciona un nuevo marco para investigar la adaptación social y emocional puesto que la inteligencia emocional jugaría un papel elemental en el establecimiento, mantenimiento y la calidad de las relaciones interpersonales". 
Con respecto a ello, se realizó una investigación a nivel mundial por The Consortium for Research on Emotional Intelligence in Organizations donde se concluía que en el cociente de éxito, intervienen un $23 \%$ de nuestras capacidades intelectuales y un $77 \%$ de las aptitudes emocionales.

Damasio, Neurólogo de la Universidad de lowa, afirma que el cerebro emocional está comprometido en el razonamiento, como lo está el cerebro pensante. Por tanto, tenemos dos inteligencias y dos cerebros, asociados a la razón y asociados a las emociones y son ambos los que van determinar nuestro empeño en la vida.

Por tanto, queremos clarificar que no podemos sustituir uno por otro, sino que ambos se complementan y se ven beneficiados tanto por el incremento de uno como por el del otro. Debemos buscar un equilibrio entre ellos, debido a que nuestra estabilidad emocional y nuestra sensación de bienestar influyen positivamente en nuestro rendimiento académico o profesional, igual que se ve perjudicado cuando nos sentimos mal. Desde el ámbito educativo, ¿Cómo crees que se sitúa la balanza?, ¿Por qué no probar con el trabajo de las emociones?, ¿Qué mejor que enseñar a conocerse a uno mismo?

\section{1.- Las cuatro paredes del sistema educativo y el trabajo de las emociones}

Las personas somos seres emocionales por naturaleza. Si las emociones se manifiestan en la gran mayoría de los actos humanos, se establece como condición indispensable, para comprender mejor a nuestros alumnos, el conocimiento de sus estados emocionales y los de los profesores.

Cañavera (2002) indica que "las necesidades afectuosas se manifiestan generalmente por la idea de pertenecer a alguien o a algo, de alegría y felicidad, de confianza, valor y seguridad en sí mismo, de luchar, crear, tener éxito, de comprensión y bienestar". Para una persona no hay mayor satisfacción que el comprobar como su trabajo tiene incidencia.

El problema del sistema educativo y de los profesores, es que nos olvidamos de todas las dimensiones de la personalidad. De hecho, podemos observar en el día a día cómo algunas de las dimensiones están totalmente olvidadas en la escuela. Una de ellas, y quizás desde nuestra perspectiva la más importante, es el trabajo de las emociones y sentimientos. Un maestro en el futuro ha de ser un buen gestor de emociones porque al fin y al cabo es lo que los niños manifiestan a través de sus conductas.

El sistema en el que viven la mayor parte de los niños, especialmente los de zona urbana por cuestiones ambientales (ruidos, polución, nivel económico, crisis, etc.), por los horarios (prisas por acudir a unos trabajos, estrés, agobio, etc.) y en conclusión, por todas las tensiones que se generan en el ecosistema, hace que se refleje que en el niño esa tensión, estrés, etc. Todas estas circunstancias hacen que no le permitan al maestro trabajar ni siquiera a nivel cognitivo, como desearía, a la vez que se ve contagiado de ese estrés desde el punto de vista individual.

A veces para dar un paso adelante es necesario como mínimo dar uno o dos hacia a tras o incluso pararse. Solo si nos paramos podemos darnos cuenta de algo, y cuando nos damos cuenta, tomamos conciencia y, tomando conciencia, es cuando es posible cambiar. 
Debemos emitir cambios que se traduzcan en una conducta mucho más operativa, equilibrada y más consecuente con nuestra propia esencia. Para esto es necesario cambiar ciertos enfoques y dejar de estar pendiente exclusivamente de los aspectos externos que nos condicionan directa o indirectamente dada la exigencia del propio sistema (individualismo, deseo de poder, de tener más dinero, ser más importante, tener más cosas...) olvidándonos con ello del SER.

Es justo en este espacio donde opera el crecimiento del individuo. Es en este reducto donde se produce el germen del desarrollo personal íntegro. Pero para ello, es necesario enfocar al interior, hacia dentro. Tenemos que localizar, determinar, y tomar conciencia de nuestras emociones, de nuestros sentimientos, de nuestras tensiones interiores, de nuestros apegos, ideales y sueños.

En esta dimensión subterránea apenas tiene acceso el hombre actual, y en consecuencia, el niño y el adolescente. Caminamos demasiado deprisa, descerebrados, tensos... en una avalancha ingente, impersonal, de un mundo preso de sus prisas y urgencias que viaja sin saber dónde, que transita hacia ninguna parte y lamentablemente, en muchas ocasiones hacia el abismo.

Es necesario parar y mirar por nuestra ventana interior hacia los paisajes internos desconocidos, observando de una forma paciente y sosegada, sin identificarnos con las imágenes, las emociones, los sentimientos, que allí ocurren. Esta identificación, en el caso de que llevemos a cabo esta tarea, crea un gran torrente de energía emocional, que si no es controlada, deriva en situaciones poco recomendables o productivas a nivel personal.

La basura emocional provoca actos descontrolados, situaciones disruptivas, conductas incorrectas dentro del aula o cualquier espacio donde se mueva y actúe el individuo. Es necesario detectar, identificar este basurero emocional en nuestro interior donde se genera nuestra mugre, la podredumbre humana. ¿Qué menos que una vez identificada, ponerle nombre y después intentar utilizar los mecanismos adecuados para cambiarla?.

El medio actual supone para el niño muchas restricciones especialmente de movimiento, es decir, de falta de experiencias motrices a través del cuerpo. $Y$ es que, el cuerpo te permite conectar con todo tu entorno $y$, esas vivencias, te permiten aprender del mismo. A través del cuerpo tomamos conciencia de lo que en él se encierra (emociones y sentimientos).

En la escuela este tipo de situaciones se ve muy limitado porque está todo muy compartimentalizado en áreas de conocimiento cuyo centro de interés radica en adquirir los contenidos específicos que en esa materia se trate y que finalmente serán fruto de una evaluación que determinará los índices de eficacia en función de la capacidad de retención de la información y el conocimiento.

En definitiva, queremos constatar que hay muchas experiencias que podemos vivir a través del cuerpo para que crezcamos en todas las demás dimensiones, de tal forma que trabajemos de una manera más global, holística, completa.

Otra forma de conocerse y conocer a los demás es utilizar el cuerpo como un templo para viajar al universo interno y conocerlo así en mayor medida. En este viaje interior, puedo conectar, no sólo con mis emociones y con mis sentimientos, sino con quien yo soy realmente, con mi esencia, mi ser, con lo más genuino, pero observándolo todo en este viaje como un testigo, sin ser partícipe de lo que veo, dentro de lo que siento, cobrando distancia, permaneciendo como un mero 
espectador, como un mero observador que identifica cosas, estados, situaciones, imágenes, emociones de rabia, dolor, apego; gestos; acciones, etc.

Todo es necesario para cambiar cualquier estructura personal y por tanto, crecer e identificar qué pasa en mi interior. ¿Cuál es la espoleta que pone en marcha el motor que desencadena conductas poco pertinentes?

Cuando he identificado esto (la identificación viene como consecuencia de un análisis profundo a través de instrumentos adecuados para tal fin: relajación, visualización, masaje, tai-chi, yoga, medios orientales y técnicas adecuadas para este fin) ya estoy en condiciones de poder cambiarlo. Ya soy consciente de ello.

Lo único que tengo es modificar, provocar, generar o producir una emoción, una energía contraria en post de un acto éticamente correcto (responsable, respetuoso, honesto, cooperativo, etc.).

Para eso, tengo que crear una emoción, un sentimiento barnizado con una idea de bien que tenga como consecuencia un acto positivo, que dé lugar a la querencia de la suma de más acciones de este carácter que determinen una actitud que sirva para condensar un hábito que desembocaría, a fuerza de hacerse de manera continua 0 repetirse de forma permanente, en un VALOR éticamente correcto bañado por esa idea de bien que hacíamos referencia anteriormente.

Este proceso simple, sencillo, permite mejorar la relación de los individuos tanto consigo mismo como con los demás, generando conductas más armónicas, equilibradas, cooperativas, de mayor sociabilidad y más humanas.

El problema es que el maestro no conoce estos procesos. En su defensa, tampoco se los han enseñado en las academias, escuelas superiores, universidades 0 centros de formación a los que ha acudido. Y por lo tanto, no puede utilizarlo como herramienta de mejora individual e impulso a la cohesión de los grupos.

Para esa modificación, es importante centrarse más en el conocimiento de sí mismo, a través de lo emocional y de los sentimientos, esto es, de la persona en un todo por medio de la posibilidad de situar al alumnado ante estas experiencias vitales, actuaciones dinámicas y vivenciales, que le hacen enriquecerse en su interior. No solamente dentro de la burbuja del aula sino también de la otra burbuja de mayor dimensión como son las paredes del recinto escolar.

\section{5.- EL YOGA COMO MEDIO DE TRABAJO DE LAS EMOCIONES EN EL AULA}

Está muy extendida la idea de que el yogui es un ser relajado, casi fuera de su entorno, que ni siente ni padece los acontecimientos que se desarrollan a su alrededor, iespecialmente los difíciles!; que son seres acorchados y que no están afectados por la fuerza de la gravedad. Pero nada más alejado de la realidad. El yogui para ser y crecer necesita contacto con esta, ha de tener muy bien apoyados "los pies en la Tierra", porque es desde ahí desde donde sacará básicamente su fuerza y el punto de apoyo para su equilibrio y su crecimiento físico, emocional y espiritual.

La palabra Yoga significa unión o reintegración. El Yoga es un conocimiento, un método, una experiencia que se adapta a las circunstancias, personalidad y 
demanda de cada persona. Su práctica nos lleva a hacia un bienestar total, ya que armoniza funciones físicas, mentales y emocionales.

El cuerpo del yogui es ágil, flexible, ligero, sensible y tiene energía en abundancia. En un cuerpo así, la mente puede lograr y manifestar plenamente su potencial.

El objetivo final del yoga es conseguir una mente estable en un cuerpo sano. Ramiro Calle nos dice: "El yoga es un método integral de mejoramiento humano. Al decir integral me refiero a que sus antiquísimos procedimientos de autodesarrollo alcanzan tanto al cuerpo como a la mente y al comportamiento, además de todas las energías y las funciones psicofísicas."

El yoga tiene una antigüedad de más de 5.000 años y es originario de la India. A occidente, apenas hace un siglo que nos ha llegado. Es una ciencia integral de la salud, una psicología práctica, una actitud ante la vida, una medicina natural y un solvente método para acopiar las energías dispersas. Incluye un gran número de técnicas que tienen un alcance preventivo y recuperativo. El yoga no es una terapia, pero es terapéutico.

Existen muchas ramas o modalidades de yoga, siendo dos de ellas el yoga psicofísico (hatha-yoga) y el yoga mental (radja-yoga), que son las dos categorías más practicadas. Cualquier edad es buena para comenzar a practicar yoga, tanto si se es adolescente como si se es una persona mayor. Nunca es demasiado pronto y nunca es demasiado tarde

\section{¿Cómo se desarrollan las prácticas de yoga?}

Práctica corporal. Ejercicios y posturas corporales que conducen a un funcionamiento saludable y equilibrado de los distintos sistemas que conforman nuestro cuerpo (sistema respiratorio, sistema digestivo, sistema circulatorio...)

Práctica respiratoria. El oxígeno es fuerza vital. Se harán ejercicios respiratorios para incrementar las energías y armonizar cuerpo y mente.

Práctica mental. Aquietar la mente en un mundo cada vez más complejo nos permite ver con claridad y mantenernos calmados. Consisten en:

- Técnicas de concentración, para aprender a fijar la mente y reeducarla

- Técnicas de meditación para desarrollar la atención y otras funciones y potencias de la mente.

- Procedimientos de autoconocimiento.

Los pilares para obtener los beneficios que nos procura el Yoga son la constancia y la ilusión.

El yoga físico es especialmente aconsejable para los niños. Mediante la práctica del mismo, el niño aprenderá a:

- Estirarse

- Respirar

- Relajarse

Igualmente es adecuado aplicar de forma progresiva técnicas sencillas de concentración, para que aprendan a ir dominando su mente. 
Es recomendable planificar las clases para todo el año.

Normalmente se desarrollan en tres partes:

$1^{\mathrm{a}}$ parte. Fortalecer los conocimientos en cuanto a posturas y conciencia física del movimiento.

$2^{\mathrm{a}}$ parte. En la segunda parte se van incorporando ejercicios de respiración

$3^{a}$ parte. Ejercicios de foco y concentración

Las clases de yoga deben ser dinámicas y muy variadas. Si se obliga a los niños a mantenerse sentados durante largo rato, posiblemente se cosiga el aburrimiento y la irritación. Pero si variamos las actividades durante la clase, los pequeños no perderán el interés. Es importante ofrecerles a los niños claridad, porque prefieren saber con antelación lo que harán. Una clase puede estructurarse, de la siguiente manera:

- Saludo

- Ejercicios de calentamiento y elasticidad

- Posturas

- Ejercicios de respiración.

- Relajación

- Envío de la paz

- Saludo final

Es importante planificar de manera que queden al final 10 minutos libres para que puedan ponerse los zapatos, recoger y ordenar sus cosas para dejar la sala igual de ordenada que se la entregaron; y para que puedan integrar lo que aprendieron.

A la hora de evaluar a los niños, estos no han de darse cuenta de que se les está evaluando. Será a través de los juegos y la observación que se verá si los niños captaron las enseñanzas o si es necesario volver atrás para reforzar los conocimientos.

Es importante siempre transmitir un cariño físico con respeto y moderación, porque habrá niños que son tímidos o que lo rechacen y éstos se sentirán excluidos por el profesor, incluso rechazados, si el maestro se vuelca más en los otros. Pero es importante crear un vínculo con los niños, así en las primeras sesiones será bueno que tanto el profesor como los niños lleven unas pegatinas con sus nombres para aprender a reconocerlos, y a partir de la segunda clase se empiezan a llamar por sus nombres y esto va generando un vínculo que es muy importante.

El número ideal de niños para trabajar es 6 o 7, pero se puede tranquilamente hasta con 12 niños. Más es difícil mantener una clase tranquila y relajada, en armonía todos juntos

En cuanto al horario de práctica, los niños pueden hacer yoga en cualquier momento del día. Su práctica por la mañana genera energía para comenzar el día. Durante el horario escolar puede revitalizar a los niños y ayudarles a concentrarse. $Y$ hacer yoga al anochecer puede relajarlos y ayudarles a dormir.

No es recomendable hacer yoga después de las comidas, así que habrá que evitar las clases con el estómago lleno, lo aconsejable es esperar al menos 90 minutos. En cuanto a la duración de las clases, no existe límite específico. Lo importante es que resulten divertidas y que el maestro tenga en mente las diferentes 
aptitudes y limitaciones de los niños. No se tratará nunca de forzar, sino de interesar. Bastará con planificar las sesiones y fluir con el estado de los alumnos.

En lo referente al lugar de trabajo la práctica del yoga no requiere un espacio específico, se podrán realizar tanto bajo techo como al aire libre, si el clima lo permite.

Para las clases en la escuela es preferible elegir un espacio que permita libertad de movimientos, en el que el niño pueda mover sus brazos sin tropezarse con los otros. También es conveniente que tenga los menores elementos de distracción posibles. Si ya la sala tuviese materiales que pudieran distraer, se debe buscar una pared lisa o despejarla y el maestro colocarse delante de ella de manera que el niño solo estuviese pendiente de él. Si son muy pequeños, se podrá, si le parece, hacer un círculo de color, con cartulina, indicando a los niños que tienen que mirar a ese círculo. Habrá que buscar en la sala un lugar donde dejen sus zapatos y otro donde dejen sus mochilas; es importante que estos lugares se mantengan todo el año, para mantener un orden que a la vez les repercutirá a ellos en sus prácticas. Mejor no usar inciensos, por si a alguno les incomoda o perjudica, por alergias, esos olores

El papel del maestro en el yoga infantil, la diversión deber ser la prioridad. E maestro ha de mostrar entusiasmo y transmitir positividad. Centrarse en hacer aquellas cosas que hagan bien, porque eso les inculcará actitud positiva y desde ahí irlos llevando a evolucionar, a fijarse nuevos "retos".

En el ámbito escolar habrá que plantearles reglas específicas sobre lo que está permitido y lo que no. Las cinco reglas más comunes son:

1. Evitar comer en clase.

2. Evitar usar joyas de ningún tipo porque podrían perderse o dañar a alguien.

3. Ir al servicio antes de que comience la clase, porque esto impedirá que en periodos tan importantes como la relajación no se vea interrumpida por la urgencia de un niño

4. Llevar ropa amplia y cómoda.

5. evitar forzar una posición que pudiera provocar malestar, el objetivo es sentirse bien.

\section{6.- EMOCIONALMENTE FELIZ}

Thomas Jefferson escribió en la Declaración de Independencia de Estados Unidos de América de 1776, que todos los hombres son creados iguales; que son dotados por su creador de ciertos derechos inalienables; que entre éstos están la vida, la libertad y la búsqueda de la felicidad.

De estos tres derechos, probablemente sea el tercero el que más sentido dé a nuestras vidas, pues sin su luz para guiarnos, ¿Qué haríamos con lo demás?. El primero y el segundo de los derechos que cita Jefferson aprestan el caballo y le abren la puerta del establo, pero es el tercero, la búsqueda de la felicidad, el que ha de llevarlo a algún lugar.

El Diccionario de la Real Academia Española define la felicidad como el estado de ánimo que se complace en la posesión de un bien; satisfacción, gusto, contento o suerte feliz.

La felicidad la podemos considerar como un estado de ánimo que se produce en la persona cuando cree haber alcanzado una meta deseada. Tal estado propicia 
paz interior, un enfoque del medio positivo, al mismo tiempo que estimula a conquistar nuevas metas. Es definida como una condición interna de satisfacción personal y alegría.

La sociedad del siglo XXI es una sociedad del bienestar. Este carácter placentero empieza a ser objetivo prioritario de mucho de los seres humanos. Es por ello por lo que debemos difundir los beneficios de la inteligencia emocional como el vehículo más completo para alcanzar la felicidad.

Las emociones han sido hasta hace poco un mundo poco estudiado ya que, como venimos desarrollando en el artículo, las sociedades han inculcado una mentalidad y estilo de vida muy mecanicista, siendo éste incompatible con el mundo emocional y, concretamente, con la conexión del yo interior. La inmersión absoluta en una rutina y el rápido ritmo que se lleva en estos tiempos dificultan o ralentizan el proceso personal, impidiendo que las personas retomen las riendas de su vida. No obstante, y basándonos en las experiencias actuales, afortunadamente esto está cambiando.

El primer paso que debemos de dar para lograr este cambio y conseguir alcanzar la felicidad ha de ser el de desconectar y empezar a tomar conciencia de uno mismo y de su alrededor, de ver aquellas cosas que nos ocurre, las personas que tenemos a nuestro lado y que cada día nos saludan, nos sonríen, nos miran a los ojos, de reaprender a utilizar los cinco sentidos para ver, respirar, escuchar, saborear y SENTIR.

Conseguir esto nos permitirá llegar a un estado más profundo de nuestra escala interior, aprendiendo entre otras cosas a escuchar la parte emocional que nos ayudará a reconducir y guiar nuestro camino.

Tras haber andado por diversos senderos para llegar a nuestro destino, la persona se encuentra en disposición de disfrutar y controlar su vida, convirtiéndose así en un ser independiente y autosuficiente, con la capacidad de automotivarse y crear sobre todo un ambiente seguro y feliz. ¿Y qué mejor que ser feliz?.

Aunque no podamos ser conscientes de ello, cada persona tiene el poder de manejar sus sentimientos y con ello hacerse feliz. Pero no debemos de olvidar que, no sólo la felicidad se centra en uno mismo sino que radica en los demás. El hecho de sonreír, de que te hagan sonreír y, sobre todo de que hagas sonreír a la persona que está a tu lado, hace que puedas lograr tantas cosas como puedas imaginar. Es el bien más preciado. ¿Qué puede valer más que una sonrisa?.

Por tanto, cada persona debería tener una lista de propósitos entre los que no deben faltar la alegría, el optimismo, el entusiasmo y la serenidad, que hacen que mejoren enormemente nuestras vidas desde todas las dimensiones (psicológica, social, física y ambiental).

De hecho, Diversos estudios han demostrado que las personas más felices suelen tener mejor salud que las que están estresadas de forma permanente, o son hostiles o pesimistas. Las causas no están claras; es posible que las personas más felices tengan un estilo de vida más saludable, o que la felicidad y otras emociones positivas estén asociadas a respuestas biológicas que protegen la salud.

Pero, ¿Existe realmente la felicidad? ¿Está en nuestras manos el poder tenerla? ¿Es permanente o momentánea? 
La felicidad es un estado psicológico que invade progresivamente toda nuestra mente, el mundo emocional y todo el cuerpo. La felicidad, además, es un estado emocional propio de los seres humanos. Sin embargo, seguramente hayamos podido escuchar a una persona decir que están completamente felices, y al paso de un tiempo, pongamos dos o tres días o incluso momentos después, parece que esa felicidad se ha ido.

¿La riqueza da la felicidad? Posiblemente si nos fijásemos en las personas que tienen un poder adquisitivo alto, supongamos que localizamos a las 5 más ricas según el estudio anual The World's Richest People realizado por la revista Forbes, pensaremos que se sienten plenamente satisfechos con su vida pero la realidad muestra lo contrario (en muchas ocasiones son interiormente muy pobres).

Diener et al. (1985), enviaron un cuestionario sobre bienestar a las 50 personas más ricas de Estados Unidos, según el listado publicado en la revista. Los resultados mostraban con sus respuestas que el $37 \%$ eran menos felices que la media norteamericana y que el $63 \%$ restante solo era un poco más feliz que la media. Además, todos coincidían en asegurar que el dinero no les había hecho más felices.

Otro de los motivos que ensalzan esta insatisfacción o malestar personal es su afán por dejarse llevar por el querer tener y no por el querer ser, que realmente constituye la esencia de la persona humana.

Finalmente, una de las manifestaciones de ser felices es la risa. Aristóteles la considerada como un buen ejercicio para la salud. La tradición oriental dotaba a la risa con un importante valor espiritual. Por otro lado, Bergson, autor del libro "La risa", se interesó por la concepción social de la risa. La sociedad impone una serie de exigencia que implican tensión y flexibilidad y la persona aprende a conformarse. La risa actúa como correctora cuando el individuo no se adapta.

Para mejorar la calidad de vida, hoy día se recurre a la terapia de la risa, risoterapia, terapia del humor, talleres de risa y clubes de la risa. La risa, por sí sola, no cura, pero sí es una buena terapia complementaria a la medicina tradicional. Sus beneficios son entre otros:

- Tener 5 minutos de risa es equivalente a tener 45 minutos de un ejercicio aeróbico.

- Una hora de angustia equivale a cinco horas de esfuerzo físico, en cuanto a la cantidad de energía consumida.

- Las risas verdaderas, explosivas, hacen mover cuatrocientos músculos del cuerpo, incluidos algunos del estómago que solo ejercitamos con la risa. Desde que nacemos hasta los seis años nos reímos unas trescientas veces al día. Ya de adultos, los que son muy risueños lo hacen cien veces y los que menos, apenas llegan a catorce.

- Cuando se produce la risa, aparecen movimientos incontrolados que mueven los músculos, estimulándolos de tal forma que ejercen un masaje sobre los órganos internos provocando la posterior relajación y su consecuente sensación de placer.

- La relajación y la respiración que se producen cuando ésta tiene lugar, está íntimamente conectada con el yoga. 
- Libera endorfinas.

Por ende, tanto en el ámbito educativo como en el personal (se puede extender a todos los ámbitos de nuestra vida), si una persona es capaz de sonreír y hacer sonreír a sus alumnos, lo puede conseguir todo. El hecho de que un maestro o una persona hagan desprender a un niño, a una persona, una sonrisa, es la mayor satisfacción personal e interior que se puede obtener. $Y$ es que, tú puedes hacer sonreír.

\section{7.- CONCLUSIONES.}

Una vez que hemos llegado y profundizado en uno de los dos pilares básicos de la formación del ser humano como son la inteligencia emocional y la felicidad, podemos ratificar su importancia, reconocer sus beneficios y apostar por el trabajo de ellos tanto en el ámbito educativo como en cualquier otro ya que es un medio que sirve para enriquecer interiormente a las personas.

Basándonos en las conceptualizaciones y modelos teóricos de la inteligencia emocional así como de su tipología, podemos corroborar que el rol fundamental que nos hacer ser más inteligentes, emocionalmente hablando, a nuestro parecer es aquella que se desarrolla de forma interpersonal. No obstante, todos los tipos de inteligencia han de estar presentes en el desarrollo del día a día del individuo. Del mismo modo, ha de haber un equilibrio entre los conocimientos teóricos y los conocimientos interiores, es decir, entre el saber conocer y el saber ser.

De hecho, estamos en un momento en el que este concepto está cogiendo auge, debido a la declinación que había en épocas anteriores. No obstante, las situaciones que se suelen dar en clase (en el ámbito educativo) de violencia escolar, agresión, etc; son debidas a que los niños no los estamos educando emocionalmente, por lo que se aboga por un estudio e implicación de los docentes en la puesta en práctica de dichos conocimientos. En relación a ello, consideramos la necesidad de implantarlos de forma intrínseca y transversal.

Por otro lado, siempre se había pensado que un alto cociente intelectual era determinante y único para que una persona tuviera éxito en la vida pero tras numerosos estudios, hemos podido comprobar cómo esta definición se refiere al cociente emocional. De este modo, confirmamos la importancia de trabajar en la adquisición de las emociones y las capacidades de la inteligencia emocional como son la empatía, expresión y comprensión de sentimientos, control de nuestro genio, adaptación, independencia, simpatía, capacidad de resolver problemas, persistencia, cordialidad y amabilidad.

Paralelamente, el término de felicidad es ambiguo en función del contexto en el que se encuentren. Así, podemos concluir que la felicidad es un estado de ánimo que se produce en la persona cuando cree haber alcanzado una meta deseada. Es algo interno que nos produce alegría y satisfacción con uno mismo además de entablar, establecer y desprender un clima y ambiente positivo. Algunos autores piensan que ésta es solo momentánea y que no puede ser completa, en cambio, no hay ningún estudio que refleje lo contrario por lo que, en nuestra opinión, siempre somos felices.

De hecho, se ha comprobado como las personas con actitud positiva tienen una salud óptima frente a aquellas que tienden a generar pensamientos pesimistas 
que, posteriormente, se verán afectados con más enfermedades y una forma física perjudicada.

En cuanto a la frase tan escuchada de "El dinero da la felicidad", podemos concluir que es totalmente incierta tras las investigaciones realizadas. Debemos apostar más por el "querer ser" y no tanto por el "querer tener".

Los aspectos que más importancia tienen para lograr la felicidad son el cariño y el afecto de las personas, entendidos en el ámbito de las relaciones personales. Ésta última es debido a que los momentos más felices suelen tener lugar en nuestra relación con otras personas. Y... ¿qué podemos hacer para conseguir ser felices? Lo fundamental es encontrar ilusiones para vivir, hacer de cada momento como si fuera el único, disfrutarlo y vivirlo al máximo.

Por ende, al hilo de las emociones y la felicidad, sabemos que la inteligencia emocional es el medio o vehículo para llegar a ella. El hecho de poder conocernos a nosotros mismos y tener la capacidad de detectar qué es lo que le pasa a la persona con la que estás hablando, hace que ésta se vea gratificada debido a la preocupación que se muestra, el interés, etc; lo que hace que se tenga éxito en la vida.

Para ello y siguiendo el camino de la felicidad, que es el que debemos de tratar de inculcar a nuestros alumnos (en el ámbito de la educación), amigos, familiares y personas (en el contexto social), apostaremos fuertemente por hacer felices a los que nos rodean así como hacerles sonreír porque con ello conseguiremos grandes cosas. Un simple gesto como es una sonrisa, puede ser a la vez muy grande y profundo.

\section{8.- BIBLIOGRAFÍA.}

Cañavera, E. (2002). Desarrollo emocional del ser humano. El Salvador: Editorial Biolúdica.

Collado, D. (2005). Tesis doctoral: Transmisión y adquisición de valores a través de un programa de Educación Física basado en el juego motor, en un grupo de alumnos y alumnas de primero de educación secundaria obligatoria. España: Universidad de Granada.

Goleman, D. (1998). La práctica de la inteligencia emocional. Barcelona: Kairós.

Goleman, D. (2008). Inteligencia emocional (Septuagésima edición). Barcelona: Kairós.

López, M. (2004). Enciclopedia de Paz y Conflictos. Eirene. Alberto Acosta Mesas. Tomo Primero. Universidad de Granada. Junta de Andalucía. Consejería de Andalucía.

Martínez, M. y Puig Rovira, J.M. (coord.). (1991). La educación moral. Perspectivas de futuro y técnicas de trabajo. Barcelona: Graó.

Nettle, D. (2006). Felicidad: la ciencia tras la sonrisa. Barcelona: Editorial Crítica, S.L.

Olivera, J. (2008). Apuntes para el siglo XXI: Educación y felicidad. Revista Apunts, segundo trimestre, 3-4.

Ortiz, A.L. (2007). Cómo alcanzar la felicidad infinita. Motivación y autoayuda. Barranquilla: Ediciones CEPEDID.

Sánchez, A. (2009). El valor de la inteligencia emocional. Jaén: Fá editorial.

Shapiro, L. y Aguilar, M. (2010). Inteligencia emocional para niños. Barcelona: Javier Vergara, Editor, S.A.

Tierno, B. (1996). Valores Humanos (primer volumen). Madrid: Talleres de editores, S.A. 